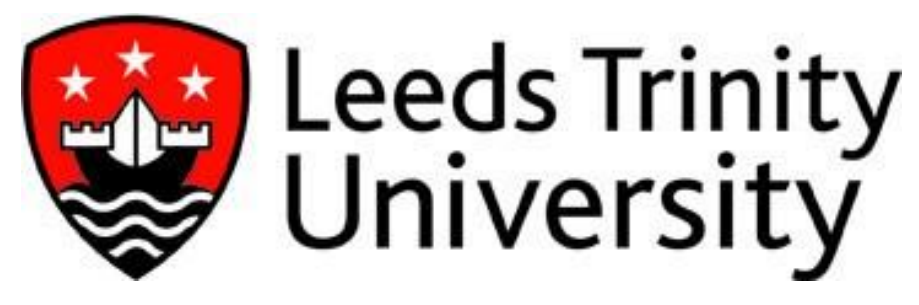

(C) 2015 The Philosophy of Education Society of Great Britain. Published by John Wiley \& Sons Ltd. This is the peer reviewed version of the following article: FULFORD, A. (2015), Higher Education, Collaboration and a New Economics. Journal of Philosophy of Education, which has been published in final form at http://dx.doi.org/10.1111/1467-9752.12152. This article may be used for non-commercial purposes in accordance with Wiley Terms and Conditions for Self-Archiving 


\section{Higher Education, Collaboration and a New Economics}

Amanda Fulford

Leeds Trinity University 


\begin{abstract}
In this paper I take as my starting point the economist, Jeremy Rifkin's, claims about the rise of what he calls the 'collaborative commons'. For Rifkin, this is nothing less than the emergence of a new economic paradigm where traditional consumers exploit the possibilities of technology, and position themselves as 'pro-sumers'. This emphasises their role in production rather than consumption alone, and shows how they aim to bypass a range of capitalist markets from publishing to the music industry. In asking how education is situated in relation to the collaborative commons, I consider the growth in technology-driven, cost-negative services as a response to the current market in higher education. This raises the issue of what we mean by 'collaboration' in the university, and how this might be different from, for example, cooperation or teamwork. In seeking to provide a richer conception of collaboration in higher education, I look to Martin Buber's concept of the relational act and the life of dialogue, and to some of the seminal work of Ronald Barnett on the philosophy and economics of higher education. The paper suggests that these concepts afford a new perspective on collaboration that amount to a new economics for education. Such economics require a radical shift in how we perceive the role of responsibility, reciprocity and the educative possibilities of conversation.
\end{abstract}




\section{Collaboration, Mutuality and Benefit in Contemporary Education}

There is much talk of collaboration in contemporary education policy and practice. There is evidence of this across all sectors of education. Primary schools are encouraged to collaborate with parents to improve educational outcomes in the early years, whilst secondary schools are urged to collaborate with primary schools, and each other, to form alliances and academy chains to maximise resources and enhance reputation. But this kind of collaboration extends beyond statutory schooling contexts: further education institutions collaborate with universities to accredit higher education courses they run, and universities collaborate with employers to provide placement opportunities for students to help address the increasingly important employability agenda. But perhaps a pause is needed here, even at this early stage, to consider what we mean by 'collaboration', and how this might be distinct from other concepts such as 'co-operation' or 'teamwork'.

In all examples cited above, the purpose of collaboration seems ineluctably tied to the production of particular, measurable, institutional outputs. Is this the same for the individual in education who seeks to collaborate? Arguably yes. Take the case of two researchers in the university who agree to collaborate on a research project. The purpose is to share expertise and resources, often with the explicit aim of securing research funding and producing an output in the form of a publication. In this example, the pursuit of collaboration, and the assessment of its success, is often driven by its perceived benefits to the respective parties. Herein lies the difference between 'co-operation' and 'teamwork' (where the etymologies suggest that the goal is the common good) and 'collaboration' which is a working together with - com labore (where the goal is the individual good or benefit). Take the case of a school that seeks to collaborate with a local university. The school might do this for the benefits that come from access to resources and reduced cost opportunities for its teachers to undertake professional development; the University, for its part, collaborates because it will gain valuable placement opportunities for its trainee teachers. In these examples, collaboration seems to tend strangely towards forms of individualism that seem contrary to the very mutuality that its Latin roots suggest.

Recently, another form of collaboration, which relies on teamwork and co-operation, has gained media attention. It makes bold claims. In April 2014, Jeremy Rifkin, President of the Foundation on Economic Trends, and bestselling author on the impact of scientific and technological changes on the economy, the workforce, society, and the environment, published his latest book. Titled The Zero Marginal Cost Society: The Internet of Things, the Collaborative Commons, and the Eclipse of Capitalism, Rifkin argues that we are witnessing the emergence of a new economic paradigm that is set to loosen capitalism's grip on contemporary society. If Rifkin is right, then we should give attention to the potential of the collaborative commons, and ask whether it hails the beginnings of a new economic paradigm for education.

\section{The Collaborative Commons: A New Economic Paradigm}

This new economic system, arguably the first since the rise of capitalism and socialism, exploits what Rifkin sees as a paradox at the heart of capitalism: the potential of technology. Within a capitalist system, producers embrace new technologies to reduce marginal cost, increase productivity, and thereby maximise profit. He argues that what capitalism did not anticipate, however, was the extent to which powerful technologies could reduce marginal cost to near zero. Where zero marginal cost ${ }^{\mathrm{i}}$ makes goods and services essentially free, they are beyond the traditional market exchange economy; moreover, it is zero marginal cost that is the trigger, Rifkin claims, for the rise of a new economic paradigm: the collaborative commons. Within the collaborative commons, individuals move from being consumers, to what he calls 'pro-sumers'. By adopting this term, Rifkin emphasises individuals' role in production rather than consumption alone; it is this that allows them to bypass capitalist markets. To illustrate this, Rifkin points to one example of how the collaborative commons have the 
capacity to change financial markets, and cites examples such as the advent of crowdsourcing and crowdfunding. Moreover, he argues that the collaborative commons are seen in other sectors: the development of blogging, social media, video production through sites such YouTube, and peer-topeer file sharing services, have had a significant negative effect on the publishing, entertainment, music and newspaper industries. Individuals are collaborating-in-common in these sectors to bypass traditional industries, and this is evidence, he claims, of this new economic paradigm at work. In response, Rifkin points to how these industries have attempted, mostly unsuccessfully, to respond by offering 'freemiums' - that is, a limited access to free services for a period, in the hope that consumers will then upgrade to a premium service at cost. ${ }^{\text {ii }}$

With the advent of the collaborative commons, the sharing of information is expanding to include actual goods. Rifkin calls this the third industrial revolution, facilitated by the 'internet of things' where everyday devices, not previously connected to the digital world, are connected to the internet. He argues that with the internet of things, we will soon be able to move to zero marginal cost in the production of energy and some manufactured goods as, for example, urban populations produce green electricity for themselves and others through domestic wind turbines and solar panels. He also points to how the market for hotels and transport could be revolutionised through the rise of technologydriven systems for renting of space (exemplified by the website Airbnb) and car-sharing schemes (such as Liftshare.com). At the cutting edge of the collaborative commons is the production and sharing of goods at near zero marginal cost through 3D printing. This suggests production, consumption and sharing not regulated by government or private enterprise, but through the social commons. Such operations do not primarily create finance capital, but, Rifkin claims, social capital where the emphasis is not on ownership, rather on access.

\section{Education and the Collaborative Commons?}

If the zero marginal cost society is extending to different sectors as Rifkin suggests, then we might question the extent to which education might be, or become, subject to such economic changes. We need to consider to what extent the everyday practices of teaching, learning, research and administration in education suggest that individuals are sharing for increased productivity, mutual benefit and sustainability. A further consideration is this: if there is such evidence, is this sharing driven by technology, facilitated by the internet of things, and do such practices have the potential to enable individuals to bypass current market in education? Arguably there is a more important question still: even if the collaborative commons were possible in education, would it be desirable? Rifkin writes in almost Utopian terms about the realisation of 'a new dream of a sustainable quality of community life', and who, in one sense, could argue against this? But what would such a life be if the school and the university were redundant? And what would be lost if property were meaningless and the market superfluous? How would the aims of education, and the values that underpin them, change in a world whose engine was an economic system driven by 'extreme productivity'? But let us return to our initial question of the extent to which education is, or might become, subject to the new economic paradigm of the collaborative commons. There is little doubt of the existence of a strong market culture in education - the starting point for a move to the collaborative commons. This is true particularly in higher education, and is evidenced in the UK by the imposition of tuition fees, by the introduction of interest-bearing student loans, by aggressive marketing of courses, by the weight given to league tables of universities and by the explicit positioning of students as consumers (Slaughter and Rhodes 2004; Molesworth et al. 2011; Brown and Carasso 2013). This is fertile ground for the emergence of the collaborative commons, especially where the role of technology is central to facilitating change. Given this, we might find that there is potential for, if not yet strong evidence of, Rifkin's new economic paradigm, and this is seen in some recent developments in educational practice and pedagogy. A number of examples in the areas of technology-mediated teaching and learning, the nature of institutions, and research and publishing, serve to illustrate this. 
Technology-mediated education has continued to rise in popularity since the Open University's first use of radio and television to bring education to a wide audience as far back as the $1920 \mathrm{~s} .{ }^{\text {iii }}$ More recently, education has harnessed the power of technology to facilitate an increase in the number of distance and blended approaches to learning, using state-of-the-art virtual learning environments. Most recently, Massive Open Online Courses (MOOCs) have been developed that aim to facilitate unlimited participation in courses accessed through the internet, and which, once set up costs are accounted for, can be delivered at near zero marginal cost. In the example of the MOOC, students are still positioned as consumers: they may have to pay to take assessments and receive certification, and by accessing an online platform, they are immersed in the advertising space that it hosts. But with sites such as YouTube, hosting services such as Slideshare and social networking sites such as Academia.edu, students and academics become pro-sumers. ${ }^{\text {iv }}$ Content can be uploaded, shared and downloaded across the virtual word at near zero marginal cost, and increasingly without the need for formal institutions such as the university.

The nature of institutions

Following the election of the Coalition government in the United Kingdom in 2010, legislation was passed that allowed the establishment of free schools - non-profit-making, independent Statefunded schools. The very basis of the free school - seen in the collaboration between parents, communities, charities or religious groups to form a school that is independent of traditional Local Authority control - is highly suggestive of the collaborative commons. Whilst the free school might be considered an example of an institution founded on the principles of the collaborative commons, there has also been a growth in the development of the virtual university - a kind of collaborative commons harnessing the potential of technology. Unlike institutions such as the Open University, the virtual universities boast no campus buildings, and are either evolutions of existing universities, or newly created 'institutions' whose common characteristics are that they exist entirely online and fully exploit the affordances of technology.

\section{(iii) Research and publication}

We might look elsewhere for something of Rifkin's vision, and to the developments around information access, and the move for universities to re-brand and re-organise their traditional libraries into technology-rich spaces re-named as information commons (Beagle 2012). The potential of such technology-driven information access and sharing is seen, for example in the rise of teachers pursuing a collaborative vision of sharing materials leading to mass distribution (Seo and Han 2013). Perhaps one of the largest-scale initiatives of this kind is the move to open access publishing giving unrestricted online access to peer-reviewed research. Consumers of 'gold' open access, publish in open-access journals, but incur significant cost for this service; but where authors provide open access through self-archiving - otherwise known as the 'green' open access the publishing market can be largely bypassed, and the research shared at zero marginal cost. In this way consumers become pro-sumers in the collaborative commons.

A word of caution is needed; we need to be clear what these different examples actually indicate. It is not that the collaborative commons is seen in activities in the university such as interdisciplinary teaching and learning, group tasks in seminars, or in students' engagement with online activities facilitated by a virtual learning environment. All these suggest simply the embracing of pedagogical approaches that move away from the lecture form of learning, and certainly exploit advances in technology; but none of this is suggestive of paradigmatic change. Students are indeed working with students, but driven more by the university and its pedagogical strategy, its desire to improve teaching and learning or levels of satisfaction, and to reduce cost. Similarly, developments in the nature of 
educational institutions do not clearly demonstrate the emergence of the collaborative commons. The free school does not provide education at near zero marginal cost, nor ever could. But again, it is difficult to see how this is an example of the collaborative commons in Rifkin's sense; the fee structures of virtual universities operate much like other brick and mortar universities ${ }^{\mathrm{v}}$, and education is not available at near zero marginal cost as it is envisaged in the collaborative commons.

Collaboration seems to remain stubbornly at the local, rather than at the national, or even global level that Rifkin conceives. There is little to persuade us that the market within which education currently operates has in some way been eclipsed, or that a new economic paradigm is imminent. What changes there are may simply be evidence of the growth in a technology-driven, cost-negative response to the current market, particularly in higher education.

Collaboration remains a messy concept. Rifkin's conception of it is somewhat superficial; for him it is simply 'driven by a deep desire to connect with others', and for the purpose of 'engaging in the deeply social aspects of life'. Whilst this is not undesirable in itself, it fails to go beyond that idea of collaboration for my own benefit, or undertaken solely out of my desire. The concepts of obligation and of responsibility (in particular, my responsibility for the other with whom I collaborate), are missing from Rifkin's account. Where my collaboration is driven by the benefit which I hope to derive from it, my gaze is oriented towards myself, and not another. I may feel a certain responsibility, but this is to myself, or my institution, to ensure that the benefit is gained. In the examples of the collaboration between the two researchers, and between the University and the school, there is mutuality of offer (in that both parties bring something to the table), and mutuality of benefit (what is offered is of value to the respective parties). It is in this kind of mutual arrangement that Paul Standish sees a form of economy at work, one that he describes as 'the closed economy of exchange' (2005: 53). It is as if in education, tutors, students and administrators are caught up in 'forms of exchange in what we might think of as a closed economy, an economy that totalises the field of concern' (p. 53). This is not a critique of collaboration per se, but draws attention to where the effects of the closed forms of exchange in our mutual arrangements encroach on other ways of thinking and acting. What such exchanges tend to exclude in education is the opening of a space for the kind of mutual relationship with the other that is marked by a focus on something other than the exchange of 'things' or of 'services'. In the closed economy of exchange there is little focus on the kind of relationship where I am responsible for another. It is this idea of responsibility in our relationships of which Martin Buber $(1958 ; 1961)$ has written, and to which I now turn to discuss.

\section{Buber: Responsibility and the 'Life of Dialogue'}

Buber describes how our human relationships can be played out by way of our encounters with each other and with language through a 'life of dialogue' (1961: 37), where to be human is always to be-inrelation through language. This mode of existence, to which he refers as an $I$ - Thou relationship, is characterised by dialogic intersubjectivity, and stands in contrast to the 'monological' I - It mode of existence in which the other is an object that exists only as part of one's own experience. ${ }^{\text {vi }}$ For Buber, the encounter with the other, and the responsibility that this brings, is indicative of an $I$ - Thou relationship, one characterised by mutuality, exchange and reciprocity. Buber puts it like this: 'Relation is mutual. My Thou affects me, as I affect it' (1958/2013: 12). But this is not reciprocity understood crudely, the espousing of a kind of marketised relationship to the other that we might talk about in terms of 'user engagement' or 'user involvement'. Such 'reciprocity' would be: 'technical dialogue prompted solely by the need of objective understanding' (1961: 37), and which constructs individuals as objects to be used to serve particular interests. ${ }^{\text {vii }}$ As such, this would be a turning away from the other. In many contemporary educational collaborations this $I$ - It relation is in operation. Collaborations in education, in which the other is merely objectified (by my expectation but for whom I have no responsibility), are, as Buber defines them, technical dialogues - or we might say, technical collaborations - only. Where the object of my collaboration is solely driven by such specific - and 
often narrow - expectations of benefit or outcomes, the richer educative possibilities that can come from an encounter with, and a responsibility for, the other, are lost in the service of securing those benefits. What marks out the relations of mutuality and exchange in Buber's work is his idea of responsibility, a radical re-understanding of the notion of accountability. Responsibility is the fundamental ethical relation embedded in the I-Thou relationship; moreover, since this ontological relation is universal, so is responsibility (Vogel 1970). It is in our living with each other, and our being in a reciprocal relationship of responsibility for the other, that we encounter each other through dialogue. This goes beyond the kind of expectation in which the other is objectified, to a meeting of the other that requires a mutuality beyond contentment, or the satisfaction from having the benefits that come from this relationship secured. Such mutuality comes from being exposed to the other, and having responsibility for the other, in the encounter of dialogue.

Perhaps we might boldly suggest here a new relation to the world, one that requires us to risk extending Buber's vision beyond the dichotomy of $I-I t$ and $I-$ Thou. Perhaps to live in 'separation' from each other (1958/2013: 31), retreating, in Buber's words, into the provinces of institutions and feelings alone, is to be in an It - It relation. ${ }^{\text {viii }}$ Buber writes of 'taking our stand' in the world and in relation. But we might say that in the It - It relation, any power that we have to take a stand is wrenched from our grip, and we are merely stood or positioned as commodities within our institutions as our subjectivities are gradually destroyed. To say that we experience the world as It - It is to come to a stark realisation of our state of subjectivation. We cannot escape the condition of the 'multifaceted total effect of regulating discourses ... [in which we are as] a disciplined body held in the sway of institutionalized authority' (Prado 1995: 56). In such a state, we are not even, to use Gabriel Marcel's language, present to each other. We are therefore incapable of the kind of mutual tie to, and communion with, the other in which an $I-T h o u$ encounter with the other is possible (Marcel 1995). In the It - It model of being, it is as if the 'institution' has engendered and valorised an indisponsibilité, an unavailability from communion.

The idea of the It - It is a bold, but arguably not unfounded extension of Buber's central idea. Can we say that the It - It is not only part of our experience of the world (and of the collaborative commons, perhaps), but also that it is creeping into the corridors of our universities? Let us take the university as an example: to make this claim would be to suggest that there has been a shift - subtle, though significant - in the positioning of key stakeholders. Perhaps we can see something of this in the following examples: in the pressure for research productivity in a culture of instrumentalism and performativity (see Saltmarsh et al 2011); in the drive to balance finances by recruiting large numbers of international students under the guise of an 'internationalisation agenda' (McClelland and Gandy 2012) and in the silencing of dissenting voices in the name of protecting the institution. ${ }^{\text {ix }}$

\section{Rifkin and Buber 'in Dialogue'}

Rifkin's new economic paradigm is predicated on a model of production and consumption within the collaborative commons, a space in which he sees potential for education, particularly higher education, to be transformed. Universities as sites of production and consumption is a well-established notion in the literature on the economics of higher education (see Collini 2012; Readings 1996). Universities produce commodities in terms of knowledge through research outputs, and of graduates suitably prepared with transferable skills for the labour market. Knowledge is currency in this system: 'Knowledge in higher education is no longer an end in itself. Knowledge is eclipsed by research that has value as a product capable of generating financial returns' (Naidoo 2005: 28). But it is not only knowledge that has a value in this economy of higher education; it is also certain types of relationship. Think of the researcher who actively seeks out international colleagues with whom to collaborate, or prioritises interdisciplinary projects in order to boost their research profile or impact potential. These are the kinds of relationship that Buber describes in terms of $I-I t$, those that instrumentalise and objectify the other. As we enter into such collaborations (or into what Buber terms 'technical 
dialogue') what is at the forefront of our minds are the benefits that might accrue to us from such collaborations. It is as if - and here I put a gloss on Buber's original - we are: ${ }^{x}$

[a]ll subdued in our actual presence and form so sternly that we recognise each other only as an expression of law ... We are dissipated and perpetuated in number, in pure numeric relation. In all this we remain solely the institution's object, and only by virtue of the institution itself do we have any nature and constitution.

On this reading, higher education - seen in terms of neoliberal market mechanisms - is in Rifkin's view, ripe for the emergence of the collaborative commons. But the university should not only be thought of solely in terms of goods and services, production and consumption. Whilst Ronald Barnett's seminal works on higher education acknowledge that the university is now understood to a great degree in terms of broader concepts of, for example, the market, competition and entrepreneurship, that is, as an 'epiphenomenon of deep global structures' (2015: 210), he also argues that it must be thought of as 'a set of universals of otherness' that include concepts such as the public, engagement and social virtue. On this reading, our engagements with each other are characterised by the kind of relationships that Buber writes of in terms of $I-T h o u$. Here, I enter into the life of dialogue not with a view to what benefits I might gain, but because it is only in relationship with the other that $I$ can truly be $I$. This is the truly ethical relation. Ronald Barnett, in discussion with Jon Nixon, puts it like this: 'Our engagements with each other and the world around us, and our depictions of the world and others around us are, in the end moral matters (Nixon et al., 1999: 573). This suggests a different purpose for our engagements through dialogue with each other than Rifkin's notion of the collaborative commons allows. Indeed, paradoxically, the notion of collaborating for one's own benefit seems simply another iteration of the capitalist system whose demise Rifkin prophesies. Any view of the university that emphasises solely its role in contributing to the economy, and yet fails to take account of what Barnett refers to as the 'emancipatory conception of higher education' (1990: 28), merely instrumentalises and objectifies; it reduces our relation to it, and our dialogue within it, into one merely of I - It. But we must be careful not see Buber's life of dialogue, experienced as $I$ - Thou , in redemptive terms, and conversely not to demonise the $I$ - It; indeed, Buber warns against this, and states that without the It, 'man cannot live' (2013: 24). Yet there remains something distinctive - and educative - about Buber's thinking of our lives lived in collaboration in institutions; something that is missing from Rifkin's account. Where our collaborations are characterised by $I$ - It relations, our interactions are narrowly focussed on how we 'use' and objectify the other to sustain and equip our own lives (2013: 28). But for Buber :'True community arises through ... taking a stand and living in mutual relation with one another' (p. 32). This is a mode of being-with, and living together, that is predicated not on the production or sharing of objects, but on our willingness to enter into dialogic relations that are truly educative. But whilst Rifkin's vision offers a 'new dream of a sustainable quality of life', Buber's is a markedly richer account, one in which there is no easy outcome, only a commitment to a life of dialogue in which my responsibility for the other is the driving force of the collaboration. To risk living in this kind of mutual relation is to accept that: 'The moments of the Thou [will] appear as strange lyric and dramatic episodes, seductive and magical ... loosening the well-tried contexts, leaving more questions than satisfaction behind them, shattering security' (p.23).

Were the university simply another industry - and neoliberal society has a view of it as a manufacturer of knowledge, and even of graduates, as 'products' (Barnett 1994: 13), then it too might be open to the potentialities of - or the risks of - (depending on your view) the collaborative commons. But Barnett makes it his business to call attention to what the university is educationally, as an institution encompassing ideals of liberal education, institutional autonomy, academic freedom, the value of critical abilities, and the preserving and developing society's intellectual culture. ${ }^{\mathrm{x}}$ The university, as Barnett imagines it, is 'an institution with a particular set of linked and intrinsic causes'; but it is not, he argues, 'normally in the business of running casinos or selling soap flakes. It has its own raison d'être' (1990: 9). What this suggests is that, whilst collaboration, in Rifkin's sense, may account for some of the reality of relationships as they exist in the contemporary university, its very existence qua university calls for relationships and dialogue that are both educative and are rooted, as in Buber, in a radically different economics. 


\section{Towards a New Economics}

Just as it is difficult to conceive for education of the richer form of collaboration that Buber's notion of dialogue and of 'taking a stand in relation' may offer, it is similarly hard to imagine a wholesale shift away from capitalism towards the collaborative commons in education. Whilst there may be a shift in some sectors of society - such as information sharing, publishing, the music industry and in energy production - towards the kind of mass collaboration that Rifkin describes, the scale of this is perhaps yet to impact on education significantly. However, is there a place for a new economics for education? Can we envision an economy not based on the closed economy of exchange in our collaborations, and specifically in the tutor-student relationship? And can our collaborations be pursued for reasons other than solely for mutual benefit? To do this would require a radical shift away from the neoliberal ideals that pervade our university discourses; but perhaps this is both naïve and unrealistic.

But there is a starting point here, a way in which we can, even in the contemporary university, give attention to Buber's 'life of dialogue' that demands we take seriously our responsibility to the other. But there is also a problem: Buber does not formulate his ethics of responsibility in terms of practical questions such as 'For what are we responsible?' or 'To whom are we responsible?' If we are to take responsibility for the other as ontologically embedded in the I-Thou relation, then this is our starting point: that we are responsible in our everyday dealings with each other, in our conversations with colleagues, administrators, managers and students. In particular, the life of dialogue and the responsibility that is ours for the other, can take place in the tutor-student relationship, particularly in the one-to-one conversations that, say, the university tutorial affords. If we give attention to the common root of the words 'responsibility' and 'respond', we make sense of the idea that we are simply responsible for responding, and that, in Buber's words: 'We practise responsibility for that realm of life allotted and entrusted to us for which we are able to respond' (Buber 1961: 92). So in Buber there is a richer conception of how we live with each other than the idea of the prosumer allows. For Rifkin, we consume (from the Latin sumere, to take) and produce (from the Latin producere, to lead or bring forth) solely for what we can gain (economically, materially, competitively). There is a giving and a taking implied here, but this is not the kind of reciprocity of the relational act; a different economics is at work here. Whilst there is some necessity for reciprocity in intersubjective relations, this cannot be demanded; it is not an obligation. For Buber, the idea of an 'ought' in the relational act denies the kind of 'real responding' that he espouses (1961: 34). He writes instead of the choice that stepping into relation involves: 'The Thou confronts me. But I step in direct relation with it. Hence the relation means being chosen and choosing, suffering and action in one' (1958/2013: 54).

But there is a potential danger here: we cannot think of responsibility in the sense of it being mutually discharged; to do so would be to risk seeing it in the same light as mutuality and collaboration in the way these have been described - at risk of the closed economy of exchange, of an I-It relation. The economics of responsibility are those of an economy of excess where my responsibility to the other is never discharged. It is one with which we live daily. It does not arise from an imperative, a set of prescribed rules, or even a general law. It cannot be reduced to a tick box list which, when completed, demonstrates that we have discharged our responsibility to the other. It is rather characterised by an attentiveness and readiness to respond to the other in our everyday relations and conversations in education. But his does not imply that our conversations have to be concerned always with profound or serious issues. Our everyday conversation can demonstrate the new economics that is at stake in our relations. To write of 'economics' is to be reminded of its etymology (in the Latin oeconomia household management), and to recognise that the moments of relation, bound together in speech, begin in the everydayness of home. Moreover, in his Postscript to I and Thou, Buber writes that conversation in the 'life of dialogue' is not 'something happening solely ... above the everyday' (p. 95). For Buber it is speech that facilitates the relational act with each other; our world of relation is 
possible in other spheres of life (with nature and with spiritual beings), but our life with others, through speech, is significant:

Of the three spheres, one, our life with men, is marked out. Here language is consummated as a sequence, in speech and counter-speech. Here alone does the word that is formed in language meet its response ... The moments of relation are here, and only here, bound together by means of the element of the speech in which they are immersed. Here what confronts us has blossomed into the full reality of the Thou. Here alone, then, as reality that cannot be lost, are gazing and being gazed upon, knowing and being known, loving and being loved (1958/2013: 71).

Such dialogic relationships of responsibility are also educative ones. In Buber's account our education is dependent on encounters that are outside of the self, in moments of relation bound by speech. In such relationships is the possibility of a different kind of collaboration, a community (not a collectivity or a collaborative commons) where there is a dynamic facing of the other: '[where there is] a flowing from $I$ to Thou ... community happens. Collectivity is based on an organised atrophy of personal existence, community on its increase and confirmation in life lived towards the other' (1961: $51)$. 


\section{References}

Barnett, R., (1990), The Idea of the University, Buckingham: Open University Press.

Barnett, R., (1994), The Limits of Competence: Knowledge, Higher Education and Society, Buckingham: Open University Press.

Barnett, R. (1999) Realizing the University (Society for Research into Higher Education) Buckingham: Open University Press.

Barnett, R., (2015), 'Editorial: On the Matter of Understanding’, Educational Philosophy and Theory, 47.3, pp. 209-213.

Beagle, D., (2012), 'The Emergent Information Commons: Philosophy, Models, and 21st Century Learning Paradigms’, Journal of Library Administration, Vol. 52, Issue 6-7, pp. 518 - 537.

Brown, R., and Carasso, H., (2013), Everything for Sale? The marketisation of UK higher education, Abingdon: Routledge.

Buber, M., (1958/2013), I and Thou, Transl. Roland Gregor Smith, London: Bloomsbury.

Buber, M., (1961), Between Man and Man, Transl. Roland Gregor Smith, London: Collins.

Collini, S., (2012), What are Universities For?, London: Pearson.

Dewey, J. (1916/2004), Democracy and Education, Carbondale, IL: Southern Illinois University Press.

Jaspers, K., (1965), The Idea of the University, London: Peter Owen.

Leavis, F.R., (1945), Education and the University, Cambridge: Cambridge University Press.

Marcel, G., (1995), The Phenomenology of Existentialism, Trans. G.S. Fraser, Chicago: Henry Regnery.

McClelland, R./J., and Gandy, R.J., (2012), 'Undergraduate regional migration in the UK: Perspectives on Local Markets and Trends for Gender and International Student Groups', Studies in Higher Education, Vol. 37, issue 8, pp. 901 - 924.

Molesworth, M., Nixon, E., and Scullion R., (2011), The Marketisation of Higher Education: The Student as Consumer, Abingdon: Routledge.

Naidoo, R., (2005), 'Universities and the Marketplace: The Distortion of Teaching and Research', in Ronald Barnett, (Ed.), Re-Shaping the University, Maidenhead: Open University Press.

Newman, J., (1853/1976), The Idea of a University, Oxford: Oxford University Press.

Nixon, J., Rowland, S., and Walker, M., (1999), 'Imagining the University: A Critical Dialogue with Ronald Barnett’, Teaching in Higher Education, Vol. 4, Issue 4, pp. 555 - 573.

Open University, (2014), ‘The Open University Story’, [Online], Available at http://www.open.ac.uk/about/main/strategy/ou-story, Accessed June 5 2014.

Prado, C. G., (1995), Starting With Foucault: An Introduction to Genealogy, Boulder CO: Westview Press.

Readings, B., (1996), The University in Ruins, Cambridge MA: Harvard University Press.

Rifkin, J., (2014), The Zero Marginal Cost Society: The Internet of Things, the Collaborative Commons, and the Eclipse of Capitalism, New York: Palgrave Macmillan. 
Saltmarsh, S., Sunderland-Smith, W., and Randell-Moon, H., (2011), '”Inspired and assisted”, or "berated and destroyed"? Research leadership, management and performativity in troubled times', Ethics and Education, Vol. 6, issue 3, pp. 293 - 306.

Seo, K., and Han, Y., (2013), 'Online Teacher Collaboration: A case study of voluntary collaboration in a teacher-created online community', Korean Educational Development Institution Journal of Educational Policy Vol. 10, Issue 2, pp. 221-242.

Slaughter, S., and Rhodes, G., (2004), Academic Capitalism and the New Economy: Markets, state and higher education, Baltimore: The John Hopkins University Press.

Standish, P., (2005), 'Towards an Economy of Higher Education', Critical Quarterly, Vol. 47, Issues $1-2$, pp. $53-71$.

Vogel, M., (1970), 'The concept of responsibility in the thought of Martin Buber', Harvard Theological Review, Vol.63, No.2, pp. 159-182.

\section{NOTES}

\footnotetext{
' In economic theory, the actual cost (of producing a good or service) makes a clam on a company's economic resources. Marginal cost indicates the additional production costs that result from producing one extra unit of a good or service. Zero marginal cost, on the other hand, refers to the situation where one additional unit of a good or service can be produced, and there is no additional cost incurred.

${ }^{i i}$ Rifkin gives the example of the music industry might offer limited access to free music to build loyalty in a fan base who will subsequently pay a premium to go to concerts to see acts in person. A further example is that of the New York Times newspaper offering access to a number of free articles online per month with the aim of encouraging subscription to a premium service.

iii See ‘The Open University Story’, [Online], Available at http://www.open.ac.uk/about/main/strategy/ou-story, Accessed June $5^{\text {th }} 2014$.

iv The use of the term 'prosumer' emphasises a role not only in consumption, but also in production.

${ }^{\vee}$ See the fee structure for the Virtual University of Pakistan, [online], available at: www.vu.edu.pk.FeeStructure.aspx accessed May $8^{\text {th }} 2015$.

vi Buber uses the following example to illustrate the $I$ - Thou and $I$ - It modes of existence:

'I consider a tree.

I can look on it as a picture: stiff column in a shock of light, or splash of green shot with the delicate blue and silver of the background. I can perceive it as movement: flowing veins on clinging, pressing pith, suck of the roots, breathing of the leaves, ceaseless commerce with earth and air - and the obscure growth itself.

I can classify it in a species and study it as a type in its structure and mode of life.

I can subdue its actual presence and form so sternly that I recognize it only as an expression of law... I can dissipate it and perpetuate it in number, in pure numerical relation. In all this the tree remains my object, occupies space and time, and has its nature and constitution' (1958/2013: 6).

vii John Dewey refers to a similar idea in Democracy and Education when he writes: 'A large number of human relationships in any social group are still on the machine-like plane. Individuals use one another so as to get desired results' (1916/2004: 5).

viii I am grateful to Professor Paul Standish for this insight.

ix In late October 2014, the UK press reported the case of a professor at a Russell Group university who was suspended from his post for 9 months whilst charges (later overturned at an employment tribunal) alleged that he had 'given off negative vibes' and undermined the authority of the former head of his department. See http://www.telegraph.co.uk/education/11187063/Professor-suspended-from-top-university-for-giving-off-negativevibes.html, Accessed 27 ${ }^{\text {th }}$ October 2014.

${ }^{x}$ See Buber's original in footnote vi.

${ }^{x i}$ Barnett's work at this point draws on ideas from John Newman’s Idea of a University (1853/1976); Karl Jaspers' (1965) The Idea of the University, and F.R. Leavis' (1945) Education and the University.
} 